\title{
SPARC and ACRL
}

\section{Working together to reform scholarly communication}

\author{
by Rick Johnson
}

\section{A} CRL and the Scholarly Publishing and Academic Resources Coalition (SPARC) have worked closely together since SPARC's inception. With the launch of ACRL's new scholarly communications initiative ${ }^{1}$, SPARC and ACRL have become even more intimate partners. While SPARC is still a relatively young organization, it has had notable successes facilitating constructive change in the scientific publishing marketplace. These successes have given SPARC a foundation from which to plan our next steps, and we look forward to implementing new strategies in alliance with ACRL's Scholarly Communication Committee and the new ACRL visiting program officer for scholarly communication.

As our two organizations move forward to achieve the goal of reforming scholarly communication, and as the ACRL Scholarly Communication Committee outlines its own objectives for the future, I would like to describe the ways SPARC expects to develop.

\section{What we've achieved}

As many CGRL News readers know, SPARC and SPARC Europe are alliances of universities, research libraries, and organizations built as a response to market dysfunctions in the scholarly communication system, which have reduced dissemination of scholarship and crippled libraries. SPARC serves as a catalyst for action, helping to create systems that expand information dissemination and use in a networked digital environment, while responding to the needs of scholars and academe.
Since its formal launch in June 1998, SPARC has advanced our members' agenda by:

- demonstrating that new journals can successfully compete for authors and quickly establish quality;

- effectively driving down the cost of journals;

- creating an environment in which editors and editorial board members claim more prominent roles in the business aspects of their joumals;

- stimulating the development of increased publishing capacity in the not-for-profit sector and encouraging new players to enter the market;

- providing help and guidance to scientists and librarians interested in creating change; and

- carying the methods and message of change to international stakeholders.

Today, membership in SPARC and SPARC Europe numbers approximately 240 institutions in North America, the U.K., Europe, Asia, and Australia; SPARC is affiliated with major library organizations in Australia, Canada, Denmark, New Zealand, the UK and Ireland, and North America.

\section{Next steps}

SPARC's priorities for the future build on our experience of the past several years. But our central objective remains to enhance broad and cost-effective access to peer-reviewed scholarship. This objective is pursued via three interrelated thrusts:

- Incubation of alternatives to current highpriced journals and digital aggregations. Actions speak louder than words, so SPARC is first and

\section{About the author}

Rick Johnson is SPARC Enterprise director, e-mail: rick@arl.org 
foremost concemed with bringing tangible change to the established system of scholarly communication. To accomplish this, we assist in launching and winning acceptance of alternative journals, organize and develop robust information communities, and create library friendly business plans to sustain innovative scholarly communication ventures. We rally market support of deserving initiatives through our publisher partnership programs and provide advisory services that help scholarly publishing initiatives operate on a sound basis.

- Public advocacy of fundamental changes in the system and the culture of scholarly communication. SPARC advocacy emphasizes outreach targeted at scholarly communication stakeholder groups (e.g., librarians, faculty, and editorial boards), as well as ongoing communications and public relations activities that publicize key issues, initiatives, and success stories. These efforts leverage the impact of SPARC's publishing partnerships, providing broad awareness of the possibilities for change and emboldening scholars to act.

- Education campaigns aimed at enhancing awareness of scholarly communication issues and supporting expanded institutional and scholarly community roles in and control over the scholarly communication process.

In addition to advocacy and educational work, ACRL has identified coalition building with higher education and scholarly associations as a high priority. These will be frutful areas for collaborative work with SPARC and will provide enhanced traction to the work of both organizations

SPARC's future activity will emphasize providing expanded practical assistance to innovative publishing initiatives that embody SPARC values, especially the facilitation of libraryscholar partnerships in support of scholarly communication. Under this umbrella, SPARC seeks to build successful publishing plans, reduce barriers to market entry, make effective use of available resources, and apply lessons leamed to other projects. Activity will cluster around initiatives to:

1) Encourage development of institutional repositories for the work of scholars. SPARC has launched a vigorous international drive for creation of "institutional repositories" for scholarship. Such repositories offer an immediate and valuable complement to the existing scholarly publishing model, while stimulating innovation that will cause the publishing
Structure to evolve and improve over time. (More on this subject, below.)

2) Support scholar-led journal publishing initiatives. When scholars are ready to take action and assert control over scholarly communication, they must have concrete options. Regardless of the future of joumals, it is through this filter that most scholars today engage with the issues. Hence, SPARC continues its support of scholar-led initiatives in which editorial boards are "declaring independence" or testing new economic models

\section{3) Develop new collaborative digital} publishing enterprises and models. BioOne (http://www. BioOne.org) has been a notable success and offers a base of experience applicable to other initiatives. Along with other SPARC engagements, it suggests the power of uniting various players in the information chainsocieties, libraries, consortia, academic computing centers, and university presses-in pursuit of shared objectives. Moving forward, SPARC will be closely involved in cultivating projects that hamess this power to offer scholars better ways of disseminating their research.

SPARC will support these kinds of ventures, including affordable altematives and open access initiatives, through a range of activities. These will aim at sharing information, applying and transferring specialized expertise (especially business and financial planning) through publication of practical manuals and guides and through the SPARC Consulting Group, and providing marketing services to qualified publishing partners.

"Gaining Independence: A Manual for Planning the Launch of a Nonprofit Electronic Publishing Venture" is SPARC's newest project to encourage planning for sustainability. Available on the Web free of charge ${ }^{2}$, "Gaining Independence" is a detailed, step-by-step guide that leads readers through the creation of a business plan for start-up and early-stage electronic publishing ventures, including digital repositories and journals. It will help universities, libraries, societies, and others conceive, plan, and implement alternatives to conmercially published scholarly and scientific information. It provides background on relevant electronic publishing models and focuses on areas of business planning that may be unfamiliar to those considering new communications initiatives.

\section{The open access opportunity}

SPARC believes that open access is an especially 
important opportunity. Both SPARC and SPARC Europe participated in the creation of the Budapest Open Access Initiative (BOAI) and have signed the founding statement of intent, which was also recently endorsed by the ACRL Board. BOAI aims to accelerate progress in the international effort to make research articles in all academic fields freely available on the Internet. The OSI Information Program of the Soros Foundations Network has committed funding of $\$ 1$ million (US) per year for three years in support of BOAI and open access projects. ${ }^{3}$

SPARC and SPARC Europe became involved in BOAI because access to knowledge is the central purpose of scholarly communication. A system built on open access offers the prospect of being less expensive to operate and of better serving scholars, the scholarly process, and society. Given these fundamentals, experiments with open access will inevitably lead us toward enduring solutions.

With others involved in BOAI, SPARC is pursuing two complementary strategies to implement open access:

- Open-access joumals. A number of SPARC's publishing partners have already achieved success as peer-reviewed open access joumals (see http:// www arl.org/sparc/core/index.asp? page $=\mathrm{c} 0$ ) and have signed BOAI, as well. Working with SPARC partners, affiliates, and members, we will expand existing efforts to demonstrate on a broader scale the possibility, benefits, and financial underpinning of new economic models for supporting the cost of publication. We also will work actively with researchers, libraries, and universities to facilitate partnerships and explore their roles in enhancing the effectiveness of scholarly communication. BOAI doesn't demand change by the societies, university presses, and other publishers; instead, it promotes the benefits of open access and seeks to demonstrate how to make such ventures economically sustainable.

\section{Online resources}

- SPARC: http://www.arl.org/sparc

- Create Change: htp://www.createchange.org

- Declaring Independence: http://www. arl.org/sparc/DI

- Gaining Independence: http://www.arlorg/ sparc/GI
- Self-arcbiving. SPARC envisions a long-term scenario in which scholarly and scientific research is openly available to users through interoperable institutional and disciplinary repositories hosted by universities, societies, and consortia. SPARC's goal during the next several years is to encourage and facilitate efforts that have the potential to move scholarly publishing toward this outcome. SPARC took a step toward this goal with the release of a major white paper, "The Case for Instituuional Repositories: A SPARC Position Paper."

Institutional repositories--in this context, defined as digital collections capturing and preserving the intellectual output of a single or multiuniversity community-provide a compelling response to two strategic issues facing academic institutions. Such repositories:

1) provide a critical component in reforming the system of scholarly communication-a component that expands access to research, reasserts control over scholarship by the academy, increases competition and reduces the monopoly power of journals, and brings economic relief and heightened relevance to the institutions and libraries that support them; and

2) have the potential to serve as tangible indi cators of a university's quality and to demonstrate the scientific, societal, and economic relevance of its research activities, thus increasing the institution's visibility, status, and public value.

Institutional repositories represent the logical convergence of faculty-driven self-archiving initiatives, library dissatisfaction with the monopolistic effects of the traditional and still-pervasive journal publishing system, and the availability of digital networks and publishing technologies. Institutional repositories build on a growing grassroots faculty practice of posting research online, most often on personal Web sites, but also on departmental sites or in disciplinary repositories. This demonstrates a desire for expanded exposure of, and access to, their work. Academic libraries can play a critical role in building this awareness through outreach programs and repository initiatives that demonstrate the practical impact of such change.

While the fundamental attitudinal shift has to come from faculty themselves, libraries are the logical institutional catalyst to introduce this shift.

The SPARC position paper explores the impact that institutional repositories can have on evolving models of scholarly communication, their implications for current stakeholders in the process, and the potential benefit they deliver to the 
institutions that sponsor them. SPARC intends its paper to facilitate a practical discussion of institutional repository policy and management issues among operational decision-makers. This discussion will necessarily engage participants from a variety of perspectives faculty as principal contributors and stakeholders, librarians as implementers, and provosts and deans as vital administration proponents. It is a discussion that readers of CERL News are urged to initiate at their institutions.

\section{Advocacy, education, and you}

SPARC has been an effective advocate for cultural changes in scholarly publishing that benefit the academic community. But SPARC will continue to be effective only to the extent that our efforts are energetically supported at the grassroots level. SPARC needs you to carry the message of change. The Create Change initiative (launched by SPARC, ARL, and ACRL) and the Declaring Independence program ${ }^{6}$ (created by SPARC with support from the Triangle Research Libraries Network) give you tools to educate and serve as activists within your community. Please use them and develop your own, as well.

SPARC has worked closely with ACRL and its other partners, alfiliates, and members to create relevant, effective solutions that witl reverberate throughout the scholarly communication system. As ACRL further develops its priorities and strategies, we would like to expand on the close collaboration that already exists and create an even stronger working relationship in pursuit of our common goals. We encourage feedback, com ments, and involvement among librarians, faculty, and administrators. SPARC can be reached by email at sparc@arl.org.

\section{Notes}

1. Ray English and Deborah Dancik, "ACRL's new scholarly communication initiative, CERL News (May 2002): 356-58. Also on the Web at http:/ www ala org/acrl/engdancik.html.

2. Visit http://wow .arl.org/sparc/GI/.

3. Detailed information on BOAI is available on the SPARC and SPARC Europe web sites at http://www.arl.org/sparc and http:// www.sparceurope.org; the text of the initiative is at hitp://www.soros.org/openaccess. To find out how you can participate in BOAI, please see hitp://www.soros.org/openaccess/help.shtml.

4. Available at http://www.arl.org/sparc/ core/index.asp?page $=\mathrm{f} 60$

5. Visit http:/www.createchange.org/

6. Visit http://www.arl.org/sparc/DV/

\section{Preserve your $\mathbf{A} / \mathbf{V}$ investment with the ideal slide archiving system}

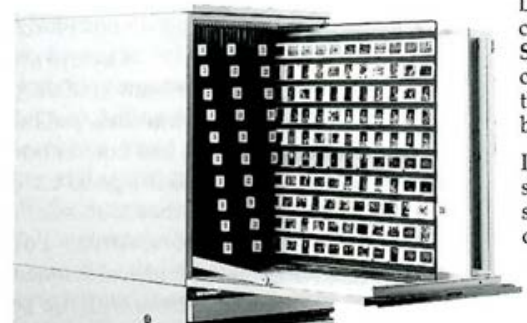

Looking for a secure, systematic way to catalog slides from years gone by? System 4000 is an innovative storage cabinet that organizes and preserves thousands of slides, making it easy to browse by subject or locate specific shots.

Its built-in light source lets you view 120 slides at once-without touching a single slide. Modular 8- and 5-drawer bases customize the system to accommodate your needs. All pieces have built-in locks, ensuring the security of your valuable resource materials.

Request your FREE Catalog to view our full line of storage systems and displays. Call 800-325-3350, fax us at 636-326-1716 or visit www.millermultiplex.com.
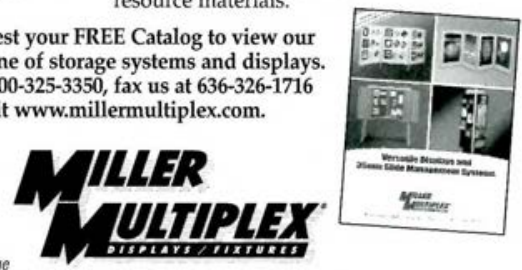